\title{
Does Area Studies Need Theory? Revisiting the Debate on the Future of Area Studies
}

\author{
Vee Chansa-Ngavej and Kyu Young Lee
}

The puzzle of whether or not Area Studies needs its own theories to progress as a social science is as old as the discipline itself. The question has been revisited several times throughout the evolution of the field, most apparent in the "area scholars vs. universalists" debate. This paper argues that area studies does not need its own specific theories per se. As an amalgamation of several social science disciplines, area studies is already well positioned to advance scientific knowledge. More attention should instead be focused on how to move from a multidisciplinary to a transdisciplinary approach, with the ultimate goal of achieving "area science." Recently renewed interest in the subfield of comparative area studies can provide a path forward. Such foundations will enable area studies to contribute to theory building in other social science subjects while also garnering respect for itself as an academic discipline. Otherwise, area studies could become a rudderless scholastic blackhole that is neither systematic nor standardized. What is at stake in this puzzle, therefore, is the very future of area studies itself.

Key Words: area studies, theoretical debates, research methodology, multidisciplinary, transdisciplinary, comparative area studies, area science

$\mathrm{T}$ he puzzle of whether or not area studies needs its own theories in order to progress as a social science is as old as the discipline itself. The question has

\footnotetext{
*Vee Chansa-Ngavej(veechansa@hotmail.com) is a Ph.D. candidate in international studies at Sogang University's Graduate School of International Studies (GSIS). He holds two Master's degrees in international relations, from the London School of Economics and the International University of Japan. Since 2006, he has served as diplomatic officer for the Ministry of Foreign Affairs of Thailand, holding a number of positions including APEC desk officer, protocol officer, and a posting in Tripoli, Libya. His current research interests are security in Northeast Asia and the South China Sea as well as the role of great powers in the perpetuation of dictatorships.

**Kyu Young Lee(kylee@sogang.ac.kr) is professor of International Relations at Sogang University's Graduate School of International Studies (GSIS). He received a Ph.D. in political science from the University of Heidelberg, Germany. He has served as board member for a number of research organizations, including as President of the Korean Association for Contemporary European Studies. He has published widely on Eastern Europe, comparative politics, and globalization as well as Korean politics, foreign policy, and society. He delivers courses on theories of area studies and European politics.
}

The Korean Journal of International Studies Vol.15, No.1 (April 2017), 85-101 
been revisited several times throughout the evolution of the field, most apparent in the "area scholars vs. universalists" debate, which centers on whether area studies should be a multidisciplinary approach in pursuit of deep contextual knowledge of a given area, or adopt an "area theory" of sorts, which would enable the discipline to move towards a more scientific approach. While world events since the $9 / 11$ terrorist attacks and the ensuing need for better understanding "the other" have shifted the pendulum in favor of area scholars, the debate still has no conclusive victor, and as such the future direction of the discipline is far from settled.

This paper puts forward two main arguments. Firstly, area studies does not need its own specific theories per se. As an amalgamation of several social science disciplines, area studies is already well positioned to advance scientific knowledge. In search of progress, area scholars should attempt to draw upon the theoretical strengths of each discipline, employing a collaborative research approach, as opposed to striving for a generic "area theory." Secondly, instead of wasting valuable academic resources on such futile debate, far more attention must be placed on how to move area studies from a multidisciplinary to a transdisciplinary endeavor, with the ultimate goal of achieving "area science." Comparative area studies, a long neglected "cousin" of area studies, can provide a solid underpinning for the path forward through its "middle path" comparative methodology.

If carried out properly, area studies could then be able to contribute to theory building in other social science subjects while at the same time garner respect for itself as an academic discipline. Otherwise, area studies risks becoming a rudderless scholastic void that is neither systematic nor standardized. What is at stake in this question of area studies and "theory," therefore, is the very future of the discipline itself. The nature of how knowledge is acquired, the methodology in which its research is conducted, the ways its findings are disseminated, and the direction of its prospective progress. As such, the thematic issues surrounding the long-standing debate are well worth a revisit.

The paper will first provide a brief, albeit necessary, overview of the history and evolution of area studies as an academic discipline, centering on the timeless question of the need for area studies to come up with its own specific theories. This will be followed by a discussion on where area studies stands today, and how it can further advance as an academic discipline, with the aim of "area science" in mind. The concluding section provides insights on the path forward, specifically focusing on the use of comparative area studies as a building block for future research endeavors. 


\section{AREA STUDIES: THE SEARCH FOR AN ACADEMIC IDENTITY}

Ever since the discipline's inception in the 1940 os, area studies has faced a struggle to find its identity. On the one hand, area scholars, particularly in the postcolonial tradition, argue that area studies can be seen as a continuation of "Orientalist" scholarship, which originated from the age of European enlightenment and imperialism (Kolluoglu-Kirli 2003, 107-108). Like the travelogues and field accounts recorded by European explorers and colonialists, country-specific case studies based on exhaustive data collection through methods such as field research and participant observation have been produced under the banner of area studies. Such methodologies, it could be argued, are the legacy of Orientalist scholarship. Since knowledge of the area under study was limited, the type of work conducted in this manner tended to be inductive, humanistic, and interpretative, a trend that has persisted in a similar fashion to how an anthropologist would approach the study of a foreign society.

On the other hand, the rise of positivism in the decades after the Second World War led to heavy criticism that area studies should develop a universal "theory" that is generally applicable across all societies and regions of the world. There were calls from rational choice advocates familiar with game theoretic models as well as political science and international relations scholars favoring the use of statistical, quantitative research data to establish patterns, generalizations, and hypotheses testing in the same vein as the natural sciences. It was hoped that "theories" could be developed for area studies, in the same manner as, say, the "balance of power theory" of realism or the "democratic peace theory" of liberalism. America's position as one of the two superpowers during the Cold War did not make things any easier for area studies scholars, as it meant that funding was tied to the US intelligence community and thereby programs were destined to serve US national interests (Cumings 1997, 10-11).

Therefore, the struggle for area studies' identity during the Cold War can be viewed as a clash between the social sciences and humanities in which the former seemed to have a definite victory until the 1970s. However, with the emergence of critical schools of thought such as postcolonial studies, ethnic studies and women's studies, new ground was opened for the humanities to claim once again an academic share in the understanding of the contemporary world (Kolluoglu-Kirli 2003, 109). 


\section{GLOBALIZATION AND THE GREAT DIVIDE}

The end of the Cold War and the ensuing era of globalization presented a different challenge to the discipline. Western liberalism triumphed to become the prevailing ideology, which led to a "global" trend of business and consumerism. In the academic world, intellectual space became free from the prohibitions of the Cold War. At the same time, technological advancements, such as the internet, gave rise to the belief among scholars in some camps that knowledge of the world was moving towards a singular, unified entity, referred to as "globalists" or "universalists." As Ludden $(2003,133)$ puts it, "universalists argue that globalization is defining a single world zone for the application of universal theory, which makes area studies irrelevant."

Perhaps no other academic exchange of views on the future of area studies was as fierce as that between Robert H. Bates and Chalmers Johnson. The former argues that the discipline had failed to generate "scientific knowledge," that area scholars had "defected" to the humanities of history, languages, and culture. In addition to the required language training, Bates (1997, 168-169) further asserts that area specialists should also be trained in statistical modeling, mathematics, and formal rational choice theories. Johnson (1997, 171-172) provides a vehement rebuttal, contending that rational choice theory does not transcend cultures. In order to truly understand a society, area scholars must study the language and culture in its individual context, which the rational choice project cannot sufficiently provide. The events of $9 / 11$ and the ensuing need for better understanding "the other" has shifted the pendulum in favor of this latter view. As Wibbels $(2007,39)$ puts it, the $9 / 11$ terrorist attacks have "underscored for many the value of country and region-specific knowledge. The more militant calls for the end of area studies have thankfully disappeared." Yet this is by no means an indication that the rationalists have waved the white flag.

In essence, the debate is between the "harder" social sciences that favors theoretical advancement, generating value-free "area theories" that are equally implementable to all regions while also equipped with predictive powers, and the humanistic camp which sees no real need for the application of such theories. To make matters worse, disciplines friendly to area studies such as anthropology have come to value deep engagement on narrow, abstract topics as opposed to wide-ranging interest in societies writ large (Pepinsky 2015). Parochialism among the disciplines has entrenched scholars on both sides of the divide, making reconciliation even more difficult.

Amidst this debate, there have been calls by some scholars for area studies to "cultivate its theoretical and methodological insight through scholarship," 
thereby realizing its "theoretical potential and develop the vision area studies needs" by being "comparative, methodologically self-conscious, theoretically ambitious and epistemologically daring” (Kennedy 1997). Yet despite this vision that has been put forward, there remains disagreement on the direction which area studies needs to take in order to progress as an academic discipline. Before providing our take on the matter, it is essential to first to examine further what "theory" in the social sciences actually entails, and assess whether or not area studies needs such "theory" for its advancement.

\section{A CLOSER LOOK AT "THEORY"}

Social science theories are far from ideal. As Schwartz $(1980,19)$ aptly observes, "the term 'pure theory' suggests something like the Kantian deduction of the categories - a process of pure reason based strictly on logical or mathematical implication, whereas in fact most of the theories in the (social sciences) disciplines are based on empirical generalization." Indeed, one of the major qualms is that they tend to be probabilistic as opposed to deterministic, lacking the power to predict, unlike theories of the natural sciences (Newton's law of gravity comes to mind). This is partly due to the fact that social phenomena is difficult, if not impossible, to replicate in a laboratory setting. The complexities of the human mind should also be pointed out. In the social world, human beings, unlike atomic particles or chemical agents, are self-conscious and can reflect on past experiences to inform reasons for shaping their future behavior (Barnett 2014, 137). Hence, even major advocates and users of rational choice theory readily admit that the theory does not explain all behavior and that irrational behavior exists (McKean 2000, 45).

Furthermore, in order to properly test hypotheses in the social sciences, the scholar must analyze the historical context of each incident in-depth and attempt to identify and isolate key variables in order to anticipate significant events of the future. Yet independent variables cannot simply be readily changed in the way that, say, a chemist or physicist is afforded such luxury in a laboratory. Case studies and historical analyses, the essential foundation for comparative and statistical models, are products of history and as such it may take a very long time to put hypotheses to the test, let alone develop theories with any predictive power. One cannot simply go back in time or replay the exact circumstances by which each phenomena occurred or policy-decision made, nor can one know when and where the next "monumental event" will occur.

As a result, there is yet to be any single overarching theory that can explain 
all social phenomena in the world. This is partly why economic experts, with all their models and diagrams, are unable to accurately predict economic crises. Likewise, political scientists and international relations scholars have utterly failed at predicting the end of the Cold War or crucial events such as the Arab Spring. Such failures provide testament that social science theories, while useful as frameworks for analyses and explanation, lack predictive powers such as those found in the natural sciences.

International relations (IR), an important sub-field of political science and a close relative of area studies, have come up with "theories" of their own, yet the definition and usage of the term "theory" in IR is in stark contrast to that of the natural sciences. Throughout the past few decades, IR scholars have managed to come up with "theories" such as realism, liberalism, constructivism, Marxism, feminism, and postcolonialism, yet there is no consensus whatsoever on the practical applicability of or even the definitions within any one particular theoretical strand. As such, "theories" in IR can be viewed more like "paradigms" or "approaches" to explain specific social phenomena through different sets of "lenses." Each school of thought would approach, for instance, the rise of China or the Syrian crisis in fundamentally different ways, as they look at the problem from varying perspectives and base their arguments on different assumptions. Debate and disagreement is therefore inevitable in international relations, as each paradigm is trying to "sell" their approach to any given problem (Kurki and Wight 2013, 32).

The insight of "theory" in international relations is crucial to our puzzle at hand since the academic discipline of international relations is very much comparable to area studies. Both are relatively young disciplines that set out to study social phenomena. Furthermore, there is still no concrete agreement among scholars in both fields as to how the disciplines should progress. Nonetheless, while international relations theories may lack the power to predict, they do provide grounded tools for the scholar to analyze events from a wide range of perspectives. Crucially, while social scientists may have difficulty with the predictive side of their theories, their theoretical frameworks provide a useful tool for identifying, analyzing, and explaining general patterns and mechanisms that arise in social settings such as political movements and the market.

The same, unfortunately, cannot be said for area studies. This logically leads to the conclusion that if area studies is to progress as a scholarly discipline, some measure of social inquiry that is grounded in analytical, dare we say, "theoretical" frameworks is called for. Only then can the area scholar be able to make use of the vast data, be it qualitative or quantitative, descriptive or statistical, inductive or deductive, idiosyncratic or nomothetic, in order to provide a comprehensive 
explanation of regions and societies in a systematic and conceptual manner.

\section{WHERE WE STAND TODAY: A "THEORY" FOR AREA STUDIES?}

There is a tendency among area scholars to discard rational choice theory as being averse to culture. As Barter $(2015,105)$ claims, "area studies scholars approach the world in terms of peoples, places, and things - prioritizing proper nouns - as opposed to discipline driven studies that may treat proper nouns as variables, or critical scholars whose esoterics may confuse more than they explain." In addition, area studies are where "good theories sometimes go to die, or at least to be reconfigured, as in theories of development, the middle class, and democracy in Southeast Asia," which indicates that universal grand theories may not be readily applicable across all areas and regions of the world (Barter 2015, 108).

When referring to "theory" itself, Lustick (1997, 177-178) makes an insightful observation by pointing out that there is a pedagogical battle for ascendancy within the social science disciplines that is taking place by virtue of hard work in the publication trenches between different academic camps who attempt to gain hegemonic control over knowledge-based institutions such as journals, endowed chairs, and peer-review panels for major grantors and departments at prestigious universities. As a result of these "wars of maneuver," the term "theory" has come to be associated with rational choice, while game theoretic modeling has been implemented to "political economy," and mathematical expertise has come to be regarded by some academic institutions as a crucial measure of competence for political scientists. Such a scenario has in fact occurred in a number of important departments across the US, with area studies having to play second fiddle to these overarching grand theories.

Yet area studies scholars have hit back, claiming that no amount of general theory could ever produce complete knowledge, or even definite partial knowledge, about any one event, person, people, country, or institution (Lustick 1997, 175). As Ludden (2003, 135) aptly puts it, "no single site can control or produce global knowledge because knowledge producers themselves are located in their world by the way they produce their knowledge, as various sites pursue diverging modalities of knowing." Essentially, understanding the local impact and manifestations of and reactions to global processes requires familiarity with and sensitivity towards individual regions (Basedau and Koellner 2007, 107). As such, globalization does not diminish but rather increases the need for areabased knowledge. 
To be fair, there have been attempts at reconciliation. For example, McKean's $(2000,30,58)$ proposition that rational choice theory, if properly understood as being based merely on two assumptions: that human beings have preferences, and that they try to pursue those preferences, can in fact be a simple yet useful tool for analysis that can examine a variety of cultural values and institutions along with other generalities in the human condition. However, such olive branches have been few and far between. It seems that in general, area scholars remain skeptical of rational choice dominance. As Hall and Tarrow (1998) suggest, "the greatest danger in the current debate over area studies is that, in the name of studying global trends or advancing overarching theories about them, the next generation of internationally oriented social science researchers will give short shrift to area based empirical knowledge."

As things currently stand, there is still no concrete agreement among academics as to whether or not area studies needs "theory," and if so, what such theory would look like. It is clear from our discussions, though, that area studies as a discipline continues its search for an identity, and that area scholars for the most part are not content at being the understudy to universal "theorists."

In our humble view, these past arguments between scholars have amounted to a futile exchange of views that places a burden on valuable academic resources. The reason that no clear winner has emerged from the debates throughout the decades is because both approaches have valid claims in their own right. What differentiates the two views, in our opinion, is the time horizon under consideration. In the past, that is, prior to the rise of positivism and the arrival of globalism, area studies may not have needed social scientific theory due to the fact that the subject itself originated as a convergence of several social science and humanities disciplines, and therefore area specialists could inherently draw upon the strengths of each discipline to conduct methodological research, as opposed to having to develop any universal "theory" per se. The advent of globalization and the advancement of technologies such as the internet have enabled knowledge of the world to become transnationally elucidated and globally disseminated, leading to increasing calls for more universal, scientific progress in the humanities, area studies being no exception.

In the following section, we will argue that area studies need not be so divided. The most productive way in which the discipline can progress and establish its future identity is through an emphasis on the transdisciplinary, as opposed to multidisciplinary, approach to scholarship. By drawing from the strengths of analyses and research methodologies of both the social sciences and humanities fields, it can be argued that if area scholars are granted sufficient resources such as funding, time, and energy, the window of opportunity could then present 
itself for area studies to take up the mantle of "area science." This would enable area experts from various social science disciplines and the humanities to come together and work on joint research to address common problems. In such a scenario, it is unlikely that "area science" would be further contested by the traditional disciplines, at least not on the heretofore points of contention, and as a result the longtime debate between "specialists" and "universalists" would finally be put to rest.

\section{FROM MULTIDISCIPLINARY TO TRANSDISCIPLINARY: TOWARDS AREA SCIENCE?}

Let us first make a terminological distinction between "multidisciplinary" and "transdisciplinary" approaches to research as follows: a multidisciplinary approach is understood to mean the act of bringing specialists from various disciplines to work together on a research project, each making a contribution by drawing on their own individual disciplinary expertise. They may collaborate on the same puzzles, thereby making the project interdisciplinary in nature, but, crucially, they each maintain a separation of their disciplines throughout that process, and findings are disseminated within their own disciplines. Likewise, when the project is completed, those specialists go back to their original disciplines to work on other projects that may or may not have relevance to area studies.

A transdisciplinary approach, on the other hand, entails the creation of a unified analytical framework, a holistic integration of collaborative knowledge that transcends the established conventional disciplines. Inevitably interdisciplinary by design, the aim of the transdisciplinary approach is to create, indeed challenge, new scholarly horizons by capturing common complexities through persistent and seamless collaborative efforts, employing a shared conceptual framework that seeks to synthesize and expand on theoretically-driven concepts, methodologies, and intellectual spaces. It is in this transdisciplinary realm which area science could be advanced (see Figure 1). 


\section{Figure 1. Multidisciplinary, Interdisciplinary, Transdisciplinary}

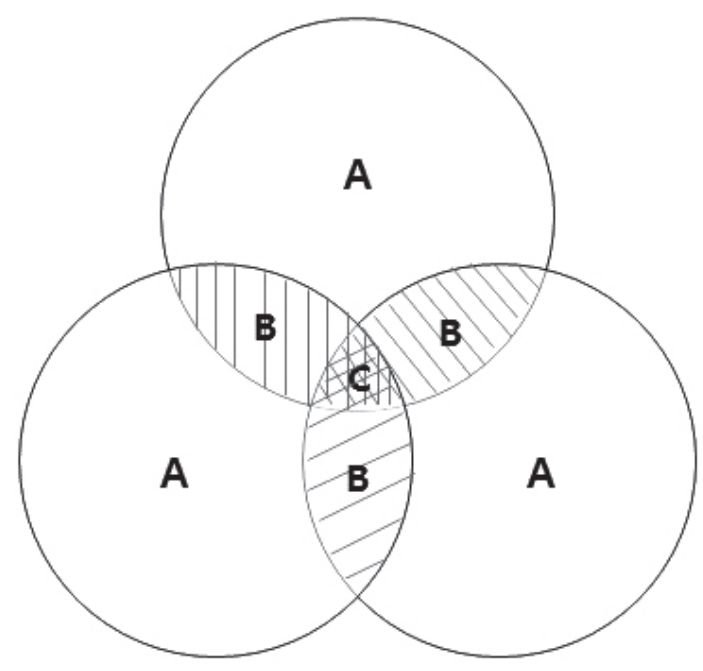
(A) $\square$ Multidisciplinary
(B) $₫$ Interdisciplinary
(C) Transdisciplinary

Source: Author's illustration

Figure 1 illustrates an abstraction of the multidisciplinary model, with each of the three circles representing individual disciplines (A). The disciplines conjoin, thereby creating an interdisciplinary process of knowledge convergence (B). The realm of area science can be developed in the transdisciplinary realm of (C). With this concept in mind, it is our firm belief that this scenario for area studies is not a distinct possibility but a very real and achievable one. After all, the blurring of the disciplines is already going on in many established disciplinedriven social sciences such as the concept of bounded rationality in economics, which borrows from psychology, or the use of statistical analysis in adding on to the comparative method in political science and sociology. Area studies is certainly no stranger to "blurring" the disciplines, and therefore must take full advantage of its prominent position as, for lack of a better expression, the sort of "middle man" among all relevant social sciences and humanities fields.

For what other academic discipline can better take advantage of its prime location across the broad intellectual spectrum than area studies? Schwartz (1980, 15) suggests that the term "area studies" asserts no particular theory of 
society or theory of culture and no particular views of relations of society and culture to history or other areas of human experience. An area is, so to speak, a cross-disciplinary unit of collective experience within which one can discern complex interactions among economic, social, political, religious, and other spheres of life. Furthermore, he contends that:

The area specialist should be open to any insight that the theoreticians within the other disciplines may have to offer, but he need not treat these theories as sacred doctrines in terms of which he passively categorizes as "facts"... the area specialist has an admirable vantage point from which to test the logical rigor and universal claims of the models he is being asked to validate...(the area specialist) may indeed find that many of the theoretical problems suggested by his own experience cut across the boundaries so sharply drawn by the disciplinary theoreticians...(the area specialist) certainly has every reason to be a critical participant in his own right in the debates surrounding the conflicting causal claims of various disciplines (Schwartz 1980, 19).

It is with this critical attitude and cooperative spirit that area scholars must uphold in their pursuit of knowledge and progress. No other discipline in the world is better positioned, nor can offer such a broad based approach to the study of its subjects. In a sense, the area specialist is fortunate to have all the tools across the social sciences and humanities at their disposal. They can draw, for instance, from the participant observation methodologies in anthropology, conduct fieldwork and interviews like sociologists, apply rational choice theoretical models from economics, and adopt various international relations theories in order to explain, analyze, and even venture to make predictions about the areas and regions they scrutinize. If they are lacking in certain areas of expertise or analyses, they can make up for those shortcomings through joint collaborative transdisciplinary research efforts that would serve to further broaden, and indeed challenge, established intellectual frontiers.

Hence, if sufficient resources such as time, energy, and funds can be secured, area studies is in fact best placed among all the disciplines to produce the systematic study of humans in a globalized world. It is also best positioned to achieve the possibility of conducting research in the manner of "area science" through transdisciplinary efforts that would require a coming together of experts from various fields contributing their knowledge and expertise to jointly tackle mutual issues of common interest. If achieved, this development would position area studies as the closest social science discipline to the natural sciences, 
perhaps even elevating area studies to the same level as other "hard" social sciences like economics or political science rather than being in their shadow.

\section{COMPARATIVE AREA STUDIES: A WAY FORWARD?}

To be sure, the goal of "area science" is an ideal abstraction, an exalted goal that is difficult to attain yet achievable. If there is any social discipline worthy of contending for the mantle of "scientific progress," it is area studies. After all, the inherent structure of area studies as an interdisciplinary assemblage in itself ideally plays into the notion of knowledge creation and scientific progress. This unique embodiment can be observed on two levels: institutional and individual. Area studies centers support the convergence of researchers from multiple disciplines, each bringing to the table a specific body of knowledge and theoretically-driven analytical framework to the collective effort. This enmeshment not only creates ample opportunity for knowledge generation, but also enables scholars to avoid the so-called "aspect blindness" referring to limitations in their own fields which may not be immediately apparent to the expert. In this manner, area studies centers are able to provide researchers with a kind of "checks and balances" system absent from other fields.

What is lacking, as we have seen, however, is a proper systematic methodology to guide the discipline towards the future. So what can be done about this shortcoming? One possible way forward is if more attention is given to comparative area studies (CAS) and the comparative methodology that it purports. CAS could then be a platform for the "methodological structure," to complement the already well-placed institutional structure of area studies as noted above. In recent years, CAS has gained increasing interest from area scholars across the methodological spectrum, for it provides a "middle path" for which scholars on both sides of the divide can employ.

Of particular note is the significant work put forward by the German Institute of Global and Area Studies, which defines CAS as a methodology which "combines the context sensitivity and knowledge of area studies with the explicit use of comparative methods and the appropriate means to generate both contributions to broader disciplinary and theoretical debates, and better insights into the cases.” As Bank (2015) elaborates further, the interest of CAS encompasses both generalization and specification, i.e. the generalization of findings beyond the "classical," intra-regional studies perspective and the better specification of single-case findings within it.

While area specialists have traditionally focused on individual countries or 
regions, groups of scholars have also been engaged in comparative research both within and among regions. CAS can be seen as the lesser known "cousin" of area studies, and while it has yet to enter the discipline's mainstream lexicon, groundbreaking attempts by scholars who have pioneered works aimed at systematically defining the term and developing a research strategy have recently appeared. Koellner, Sil and Ahram $(2016,1)$ contend that CAS may be better understood as an effort to "balance the contextualized insights generated by traditional area studies with the logic of comparative analysis as applied to intra-, inter-, and cross-regional empirical research...it is not just the leverage afforded by the comparative method that drives CAS; it is also the possibility for recognizing theoretically significant points of convergence and divergence in processes unfolding in different spatio-temporal contexts."

Another benefit of CAS is that it makes no claim, explicit or implicit, that any one social process, causal mechanism, level of analysis, or master variable should be privileged in the narratives constructed to analyze comparable cases. Furthermore, CAS is also uniquely flexible when it comes to methodology, since it comes with no set of prescribed menu of methods or toolbox of techniques. From the perspective of CAS, approaches that combine qualitative and quantitative analysis are not so much a rival but one of a multitude of possible research strategies (Koellner, Sil and Ahram 2016, 10). Significantly, as the "new kid on the block," CAS is still free from the domineering influence and presence of any particular academic paradigm, and thus in principle it is exceptionally positioned to be employed as a methodology for expanding areabased knowledge through the development of research programs however its practitioners see fit.

CAS can take many different forms, the prominent ones being intra-regional, inter-regional, and cross-regional comparative studies (see Table 1).

Table 1. Three Types of CAS

\begin{tabular}{|c|l|l|}
\hline \multicolumn{1}{|c|}{ Type } & \multicolumn{1}{|c|}{ Unit of Comparison } & \multicolumn{1}{c|}{ Example } \\
\hline Intra-Regional & Entities within a specific area & $\begin{array}{l}\text { Post-Communist regimes in } \\
\text { Eastern Europe }\end{array}$ \\
\hline Inter-Regional & Comparing different areas as entities & $\begin{array}{l}\text { Regional integration processes of } \\
\text { Europe and Asia }\end{array}$ \\
\hline Cross-Regional & Comparing entities from different areas & $\begin{array}{l}\text { Economic development among } \\
\text { Latin American and African } \\
\text { countries }\end{array}$ \\
\hline
\end{tabular}

Source: Adapted from Basedau and Koellner $(2007,110)$ 
In Table 1, Intra-regional comparisons are perhaps the most familiar form within the field of comparative politics and the most compatible approach with traditional area studies. It entails the comparison of entities within areas, for example Post-communist political regimes in Eastern Europe. Inter-regional comparisons, comparing different areas as analytical units, such as the regional integration processes of Europe and Asia, are relatively rarer. The focus of such research is usually on broad or transformational processes that can affect large areas of the world. The final form, Cross-regional comparisons, compares entities from different areas, such as economic development among Latin American and African countries. This typically involves quantitative and/or qualitative comparisons of similarly defined units selected from different areas or regions but with close attention given to the complexities and controversies present in the studies of each of the individual units.

Each comparison type can be employed according to the individual researcher's study design, depending on the focus and attention required to the units of analysis. Essentially, all three comparison types can yield important research findings that can then be used as building blocks for future research. Taken together, the CAS project can provide knowledge from both an inductive and deductive manner. It is useful for both the formulation and testing of hypotheses. In sum, its purpose is to both generate and confirm knowledge simultaneously. If deemed necessary, theory-building, perhaps even with predictive powers, could eventually emerge from this practice as an additional benefit of CAS in the future.

\section{CONCLUSION}

Knowledge of the world is infinite. It is impossible to truly "know" and "understand" the world in all its contextual complexities without studying about different areas and regions in detail. This naturally requires an inductive approach to the study of a given area, which would serve as a building block for hypotheses that would eventually lead to a deductive, top-down approach that could then be tested on other areas. To do so, the area scholar does not need to come up with any generalizable "area theory" per se, since area studies in itself requires the fusion of knowledge from various social sciences and humanities disciplines, each of which already possess their own sets of inquisitive arsenals, tools that can be readily applied by the area scholar to collect data, conduct research, and provide analysis.

That being said, the study of an area or region cannot be fully complete 
without a comprehensive and holistic approach that incorporates all available means for fact gathering and knowledge production. Neither anthropological fieldwork nor historical analysis nor rational choice assumptions nor international relations theories on their own is sufficient for this monumental task. A combination, indeed the amalgamation, of these approaches is necessary. Hence, transdisciplinary action among the various fields is in order.

While a general "theory" may not be needed for area studies, it is nonetheless crucial that social sciences and humanities methodologies be employed as appropriate to each research topic or question in the conduct of area research. Area studies must position itself delicately within the broad scholastic spectrum and take advantage of the intellectual symbiosis its unique position allows for. Only then can area studies have proper direction and garner respect as a discipline in itself. CAS, a hitherto neglected cousin of area studies, can greatly contribute to systematic studies of social phenomena as well as generate the data for testing and modifying concepts of universalistic theory. In this regard, it is encouraging to see increasing attention being given to CAS in recent years, for it can only be beneficial to the future of area studies.

To be sure, area scholars, as they have been ever since the discipline's inception, still find themselves in a precarious position. They fully belong neither to the social sciences nor humanities camp. Nonetheless, the inherent structure of area studies as an interdisciplinary endeavor in itself ideally plays into the notion of knowledge creation and scientific progress. What has been lacking is the methodological structure to guide the discipline forward. Hampered by decades of fruitless ontological and epistemological debates, CAS and its comparative method may at long last provide a "middle path" that can propel area studies to the forefront of social scientific research.

If the idealized intellectual convergence can be attained, then over time, knowledge of areas and regions of the world will expand and be studied in greater detail. The scope and depth by area experts who employ research and analytical tools from various disciplines will also further deepen. As a result, area studies has the very real potential to elevate itself to "area science," which would in turn enable the discipline to use its vast wealth of empirical quantitative and qualitative data that have been acquired through various methodologies to test hypotheses and formulate generalizable theories, creating bodies of knowledge which may, in time, even offer predictive powers in a similar fashion to the natural sciences. At that stage, the mandate for area studies would be welldefined, and there would be little need for such fierce arguments and exchange of views as to the position of area studies among the disciplines. In such a scenario, the debate regarding area studies' identity could finally be put to rest. 


\section{REFERENCE}

Bank, Andre. 2015. "”How to Conceptualize Area Studies: Thesis 2 Comparative Area Studies and Middle East Politics after the Arab Uprisings." AntiThesis 4, 22-27.

Barnett, Michael. 2014. "Constructivism.” In John Baylis, Steve Smith and Patricia Owens eds., The Globalization of World Politics (International Sixth Edition). Oxford: Oxford University Press, 130-143.

Barter, Shane J. 2015. "Area Studies, Asian Studies, and the Pacific Basin.” Geographical Review 105(1), 105-119.

Basedau, Matthias and Patrick P. Koellner. 2007. "Area Studies, Comparative Area Studies, and the Study of Politics: Context, Substance, and Methodological Challenges." Zeitschrift für Vergleichende Politikwissenschaft 1, 105-124.

Bates, Robert H. 1997. "Area Studies and the Discipline: A Useful Controversy?" Political Science and Politics 30(2), 166-169.

Cumings, Bruce. 1997. "Boundary Displacement: Area Studies and International Studies During and After the Cold War." Bulletin of Concerned Asian Scholars 29(1), 6-26.

German Institute of Global and Area Studies. Accessed at https://www.gigahamburg.de/en/idea (December 19, 2016)

Hall, Peter A. and Sidney Tarrow. 1998. "Globalization and Area Studies: When is Too Broad Too Narrow?" The Chronicle of Higher Education (January 23), 1-5. Accessed at http://www.chronicle.com/article/ GlobalizationArea/99332/(December 19, 2016).

Johnson, Chalmers. 1997. "Preconception vs. Observation, or the Contributions of Rational Choice Theory and Area Studies to Contemporary Political Science." Political Science and Politics 30(2), 170-174.

Kennedy, Michael D. 1997. "A Manifesto (of sorts) for Area Studies." The Journal of the International Institute 4(3) (Summer). Accessed at http:// quod.lib.umich.edu/j/jii/4750978.0004.302/--manifesto-of-sorts-forarea-studies?rgn=main;view=fulltext (December 19, 2016).

Koellner, Patrick, Rudra Sil, and Ariel Ahram. 2016. “Comparative Area Studies: What It Is, What It Can Do.” Paper presented at the $5^{\text {th International }}$ Crossroads Asia Conference:Area Studies' Future (September 22-23).

Kolluoglu-Kirli, Biray. 2003. "From Orientalism to Area Studies." The New Centennial Review 3(3), 93-111.

Kurki, Milja and Wight, Colin. 2013. "International Relations and Social Science.” In Tim Dunne, Milja Kurki and Steve Smith eds., International 
Relations Theory: Discipline and Diversity, 3rd Edition. Oxford: Oxford University Press, 14-35.

Ludden,David. 2003. "Why Area Studies?” In Ali Mirsepassi, Amrita Basu and Frederick Stirton Weaver eds., Localizing Knowledge in a Globalizing World: Recasting the Area Studies Debate. Syracuse: Syracuse University Press, 131-136

Lustick, Ian S. 1997. “The Disciplines of Political Science: Studying the Culture of Rational Choice as a Case in Point.” Political Science and Politics 30(2), 175-179.

McKean, Margaret A. 200o. "Rational Choice Analysis and Area Studies: Enemies or Partners?" In Neil L. Waters ed., Beyond the Area Studies Wars: Toward a New Institutional Studies. Hannover/London: Middlebury College Press, 29-63.

Pepinsky, Thomas B. 2015. "How to Make Area Studies Relevant Again." The Chronicle of Higher Education (February 12). Accessed at http://www. chronicle.com/blogs/conversation/2015/02/12/how-to-make-areastudies-relevant-again/(December 19, 2016)

Schwartz, Benjamin I. 1980. "Presidential Address: Area Studies as a Critical Discipline." The Journal of Asian Studies 40(1), 15-25.

Wibbels, Erik. 2007. "No Method to the Comparative Politics Madness." Comparative Political Studies 40(1), 37-44. 